Revista Temas Socio Jurídicos

Vol. 38 No 77 Julio - Diciembre de 2019

ISSN: 0120-8578

ISSN electrónico: 2590-8901

\title{
PERSPECTIVA Y ENFOQUE DE GÉNERO: HERRAMIENTA PARA LA TOMA DE DECISIÓN JUDICIAL ${ }^{1 *}$
}

\author{
Natali Niño Patiño $2 * *$
}

Recibido: Octubre 10 de 2019

Aprobado: Noviembre 13 de 2019

\section{RESUMEN:}

El presente artículo tiene como propósito principal pensar el enfoque de género en el marco de la decisión judicial, con el fin de determinarlo en referencia a los mandatos constitucionales contemporáneos y los modelos de justicia, los cuales decantan y ponen en evidencia la discriminación basada en el género, producto de la construcción de estereotipos y la asignación de roles en la sociedad.

Palabras claves: Perspectiva de género; enfoque de género; violencia; decisiones judiciales.

Citar este trabajo como: Niño, N. (2019). Perspectiva y enfoque de género: herramienta para la toma de decisión judicial. En: Temas Socio-Jurídicos, 38(77), pp. 11-28. DOI: https://doi.org/10.29375/01208578.3741

1 El presente artículo es producto de la investigación tituladas "Perspectivas pedagógicas: Herramientas para la construcción de ambientes de paz en Colombia”, que se adelanta en el marco del Observatorio de Paz de la Universidad Libre.

2** Filósofa y abogada. Especialista en Filosofía del Derecho y Teoría Jurídica, magíster en Filosofía del Derecho y Teoría Jurídica, Docente investigadora del Observatorio de Paz de la Universidad Libre. Docente en pregrado de Historia de la Filosofía y Lógica Jurídica. miembro del Grupo de Investigación de Estudios Constitucionales y de la Paz, docente de investigación del Instituto de Posgrados de la Universidad Libre, respectivamente. CV. ORCID: https:// orcid.org/0002-7560-8008. Correo electrónico: natali.ninop@unilibre.edu.co 


\title{
GENDER PERSPECTIVE AND APPROACH: TOOL TO TAKE COURT DECISIONS
}

\begin{abstract}
:
The main purpose of this paper is to reflect on gender approach in the framework of court decisions, in order to define it in reference to contemporary constitutional mandates and models of justice, which consider and demonstrate that gender discrimination is the result of building stereotypes and appointing roles within the society.
\end{abstract}

Keywords: Gender perspective; gender approach; violence; court decisions.

\section{PERSPECTIVA E ENFOQUE DE GÊNERO: FERRAMENTA PARA A TOMADÁ DE DECISÃO JUDICIAL}

\section{RESUMO:}

O principal objetivo deste artigo é refletir sobre o enfoque de gênero no âmbito da decisão judicial, a fim de determiná-lo com referência aos mandados constitucionais contemporâneos e aos modelos de justiça, que decantam e põem em evidência a discriminação baseada em gênero, produto da construção de estereótipos e a atribuição de papéis na sociedade.

Palavras-chave: Perspectiva de gênero; Enfoque de gênero; Violência; Decisões judiciais.

\section{INTRODUCCIÓN}

Los Estados constitucionales contemporáneos -a diferencia de los Estados constitucionales clásicos- han construido herramientas que permiten la protección y materialización efectiva de los derechos humanos, en cada uno de los ámbitos de la vida de las personas. Sin embargo, en la actualidad diferentes estudios muestran cómo a grupos de seres humanos que sufren mayores vulneraciones ${ }^{3}$, les es difícil acceder a las instituciones jurídicas para resolver sus problemas. Pero esto no es lo más grave: hay evidencias que muestran que, en los espacios judiciales, las personas que son más vulnerables pueden enfrentarse a prejuicios que generan discriminación ${ }^{4}$.

3 Para mayor información, pueden consultarse los textos de Nancy Fraser y Axel Honneth, específicamente el texto ¿Redistribución o Reconocimiento? (2018).

4 En el texto Rés negras, juízes brancos: Uma análise da interseccionalidade de gênero, raça e classe na produção da punição em uma prisão paulistana, de la profesora Dina A. (2017), se muestra cómo los jueces fallan con base en creencias que generan discriminación. 
La mujer, específicamente, sufre en los diferentes escenarios una especial vulneración, esto debido a la violencia directa e indirecta a la que se ve sometida en los espacios -tanto públicos como privados- donde la violencia y el acoso se presentan en una mayor medida y en los cuales el origen, la causa y el impacto se forman de una manera diferenciada. Por causa de lo anterior se han requerido modelos de justicia que explican la perspectiva de género y con ello, la construcción de un enfoque de género que logre comprender el problema y por lo tanto, plantear soluciones, desde los intereses específicos de la mujer.

A partir de lo anterior, el presente artículo pretende mostrar cuáles son los elementos que se deben tener en cuenta al momento de la toma de decisión judicial en los casos de violencia en contra de la mujer ${ }^{5}$. Lo anterior con el fin de materializar el derecho a la igualdad, y permitirle a la mujer mayores garantías al momento de reivindicar sus derechos. Para este propósito, el texto pretende mostrar la necesidad de la inclusión de un enfoque de género, justificada a partir de una perspectiva de justicia propia del feminismo en la toma de decisión judicial, específicamente en los casos de violencia contra la mujer, como una forma de corrección de la decisión judicial que implique que las decisiones no solamente cumplan con un criterio de legalidad sino de justicia.

Para lograr lo anterior, en la primera parte mostraré cómo la mujer se encuentra en un ambiente hostil de violencia en el que puede evidenciarse la materialización de la violencia estructural en la toma de decisión judicial. En la segunda parte, distinguiré los conceptos de perspectiva y enfoque de género, proponiendo una forma de comprender los mismos. Por último, en la tercera parte, mostraré cómo en los países en América Latina, los tribunales constitucionales han indicado la necesidad de que la jurisdicción aplique el enfoque de género en cada una de las sentencias, lo anterior bajo la hipótesis de que existe un mandato en el derecho que impone la obligación a cada uno de los jueces que toman decisiones en el marco de casos de violencia contra la mujer, de aplicar el enfoque de género y por lo tanto, habría que decantar en qué consiste el instrumento. El método que se utiliza para el desarrollo del trabajo es el análisis de texto, el análisis de sentencias judiciales y la construcción conceptual para la comprensión de un problema específico.

5 La palabra género comprende una complejidad de dimensiones entre las que forman parte el sexo, la identificación de género y el reconocimiento social. Esto hace que la categoría de análisis sea amplia y, por lo tanto, sectores de la población que han estado sistemáticamente discriminados, como, por ejemplo, los homosexuales, las lesbianas, las personas transexuales, entre otros, sean acogidos por el concepto. Sin embargo, el presente escrito se limitará a la mujer, la cual es marcada por creencias basadas en el sexo femenino y que determinan a un sector de la población para el cumplimiento de ciertas expectativas. Estas creencias son las que generan discriminación. 


\section{Mujeres y violencia: una lectura desde Galtung}

Para intentar abordar la problemática de la violencia en contra de la mujer propongo entender el problema de las mujeres desde la definición de las diferentes formas de violencia que plantea Galtung (1998), quien señala que la violencia puede presentarse de dos formas: violencia directa y violencia indirecta. La violencia indirecta implica, por un lado, la violencia cultural, junto con violencia estructural, la cual, según Galtung, es la parte invisible en la que la sociedad oculta formas violentas que generan discriminación, a través de creencias y dispositivos jurídicos y políticos. Por otro lado, la violencia directa es aquella que es visible y que se ve reflejada y registrada en el cuerpo, específicamente en el cuerpo de las mujeres.

La forma como se manifiesta la violencia indirecta es, por un lado, la violencia cultural, la cual se presenta en las creencias de las personas que generan estereotipos y estos implican una forma de discriminación, como por ejemplo, la creencia de que la mujer debe ser la cuidadora de la casa y tener una carga diferenciada en las tareas del hogar, un trabajo invisibilizado y por tanto, no remunerado, lo que le genera una responsabilidad adicional, distinta a la que puede tener el hombre. Otro ejemplo es el comportamiento "debido" e "indebido" de las acciones de la mujer, lo que hace que se le culpabilice de ciertos comportamientos, minimizando la denuncia, pero también responsabilizando a la mujer, como pudo evidenciar la sentencia de Campos de algodoneros vs. México, según lo señala el siguiente informe:

[...] los referidos funcionarios públicos actuaron con base en un estereotipo sobre los roles sexuales de las mujeres, condicionando el acceso a sus derechos a un determinado tipo de comportamiento moral considerado estereotípicamente correcto, lo cual provocó que minimizaran las denuncias por las desapariciones de mujeres y culparan a las propias víctimas de su suerte, ya fuera por su forma de vestir, por el lugar en el que trabajaban (maquilladoras), por el lugar de su desaparición (bares o restaurantes) o por caminar en las calles de noche. (Poder Judicial de la República de Chile, 2019, p. 51)

Como se puede ir decantando, la violencia cultural permea las instituciones jurídicas y con ello, se genera lo que Galtung denomina violencia estructural, que se manifiesta porque los dispositivos jurídicos reproducen y legitiman la violencia cultural. En el caso que referenciamos, los agentes que toman decisiones revictimizan a las mujeres y las culpabilizan de los actos violentos, como se puede observar en el comunicado del Comité para la Eliminación de la Discriminación contra la Mujer (CEDAW, por sus siglas en inglés) en el caso R.K.V vs. Turquía: "Los estereotipos de género se perpetúan a través de varios medios e instituciones, como son las leyes y los sistemas judiciales y pueden ser perpetuados por agentes estatales de todas las esferas y niveles de la administración, así como por 
agentes privados..." (2010, párr. 8.8). En resumen, la violencia estructural legitimada por una violencia cultural se manifiesta en las instituciones políticas y jurídicas que impiden el acceso a las mujeres de una manera igual y equitativa a la justicia.

En América Latina, las mujeres son las que más denuncian los actos de violencia y acoso; sin embargo, las cifras en cada uno de los países no reflejan la situación real de las condiciones a las que se ven sometidas día a día, pues al existir violencia estructural en contra de la mujer, estamos en presencia de casos de violencia que no pueden ser evidenciados, es decir, las mujeres están sufriendo una experiencia de injusticia por sufrir discriminación, pero al legitimarse bajo creencias e instituciones, esta experiencia queda oculta e invisible.

Ahora bien, las creencias que generan una forma de violencia oculta se pueden ver materializadas en sentencias judiciales. Así por ejemplo, podemos traer a colación el famoso caso mini falta en España en el que se condena a un empresario a pagar una multa a su empleada de 16 años, a quien el empresario le tocó sus partes íntimas y le dijo que si se acostaba con ella le renovaría el contrato. A pesar de que la sentencia falló en contra del empresario, la forma como se expresó el juez generó ciertas sospechas. Por ejemplo, el juez indica que la empleada provocó al empresario por sus trajes y sus vestuarios en cortos, a pesar de que en el expediente se probara que el día en que se cometieron los hechos la mujer se encontraba con pantalones.

En Colombia, la Corte Constitucional mostró en el caso Bárbara, que el juez de primera instancia utilizó un lenguaje poco apropiado, refiriéndose a la accionante como mitómana, con tendencias a decir mentiras, y con baja autoestima debido a su aspecto físico, lo cual generó discriminación ante el caso de una mujer que ha sido víctima del conflicto ${ }^{6}$, acusándola de decir mentiras por denunciar hechos de violencia sexual en el marco del conflicto armado colombiano.

En Brasil, el estudio de la profesora Dina Alves $^{7}$ (2017) mostró cómo el sistema judicial penal -en el que hombres, blancos y clase alta que son competentes para encarcelar en la prisión paulistana a mujeres con una

6 A continuación presento la forma como se expresó el Juez: “(...) que dan cuenta no solo de la mitomanía de ella de sobreactuarse y decir mentiras. (...) su desempeño en la organización era conflictivo y con tendencias a decir mentiras, observando una baja autoestima, tal vez por su aspecto físico, por cuanto presentaba serios problemas dentales por los que se tapaba permanentemente la boca con su mano o una bufanda" (Corte Constitucional Colombiana, 2018, folios 29 y 30 de la sentencia).

$7 \mathrm{El}$ artículo tiene como hipótesis la siguiente: "O trabalho sugere que o sistema de justiça penal funciona como instrumento de dominação racial, pois é na sua administração que se manifesta de forma explícita a intersecção dos eixos de vulnerabilidade -delineados por raça, classe e gênero- na produção de categorias de indivíduos puníveis." 
suerte de categorías específicas, a saber: pobre y negra, que trabajaban principalmente en ventas en la calle-, se reproducen estereotipos de discriminación basados en raza, género y clase para imponer mecanismos de dominación a mujeres que han sido sistemáticamente vulneradas.

Por último, en Estados Unidos, el caso Price Waterhouse vs. Hopkins, en el que Hopkins señalaba que la empresa Price Waterhouse la había discriminado por construcciones de estereotipos y le habían impedido al ascenso por motivo de que la mujer no se comportaba de manera femenina, no utilizaba maquillaje y no utilizaba vestimenta femenina, la Corte Suprema de los Estados Unidos, garantizó los derechos de Hopkins, obligando a la empresa a reivindicar el daño, por tratarse de una discriminación por razones de género.

\section{Perspectiva y enfoque: una propuesta conceptual}

En el discurso jurídico en América Latina se han construido dos conceptos específicamente para hablar de la necesidad de incorporar miradas y herramientas diferenciales para la solución de los problemas específicos de las mujeres. Estos conceptos son enfoque y perspectiva, los cuales me gustaría precisar con el fin de organizar el debate sobre el problema.

El concepto gender perspectives fue desarrollado en la IV Conferencia sobre la Mujer en 1995. En esta ocasión se utilizó el concepto en dos sentidos: por un lado, el concepto mainstreaming a gender perspective ${ }^{8}$, que buscaba que se priorizará el discurso sobre la mujer en los diferentes escenarios -intelectuales, políticos, culturales, etc.-, pero sobre todo, que se escucharan las propuestas de las mujeres en las agendas políticas; por otro lado, el concepto gender perspectives ${ }^{9}$, el cual buscaba que se implementara dentro de la política pública la inclusión de los problemas específicos de la mujer a partir del análisis de estos, con perspectiva de género.

Estos conceptos (gender perspectives and mainstreaming a gender perspective) fueron traducidos como perspectiva de género, término que acuñan varias de las instituciones en América Latina, como lo son la Corte Interamericana de Derechos Humanos, y diferentes tribunales constitucionales como el Tribunal Constitucional de Chile, Argentina, México, Perú, entre otros.

8 La IV Conferencia Mundial sobre la Mujer señaló la necesidad de impulsar los discursos puestos por las mujeres en las agendas políticas a nivel mundial: "Noting the lack of recognition and support for women's contribution (...) paragraph 252 calls for an active and visible policy of mainstreaming a gender perspective." (IV Conferencia Mundial sobre la Mujer).

9 Además, la IV Conferencia Mundial sobre la Mujer destacó la necesidad de: "Use gender perspectives in economic policy making; examine the relationship between unremunerated work and poverty; provide new and additional financial resources to target women living in poverty; and integrate a gender perspective into lending programmes, including structural adjustment programmes" (IV Conferencia Mundial sobre la Mujer). 
Además de estos conceptos, también se incluye dentro del lenguaje jurídico el concepto de enfoque de género. Los enfoques tienen como propósito principal establecer herramientas metodológicas que permitan la revisión de los problemas. En general encontramos a nivel internacional el enfoque de los derechos humanos, en el que los Estados se encuentran obligados a diseñar política pública teniendo en cuenta una herramienta metodológica que les permita decantar la protección y defensa de los derechos humanos. El enfoque de los derechos humanos limita el abuso del poder, el cual se desarrolla como un método dentro de la construcción de política pública.

En el caso de Colombia, el tribunal constitucional en los diferentes pronunciamientos utiliza la palabra perspectiva y enfoque de género como sinónimos y por su parte la Comisión de Género, de la Jurisdicción Especial para la Paz, emanó un documento para explicar los criterios que se deben tener en cuenta en el momento de establecer la violencia sexual y de género en el marco del conflicto armado interno, en el que señaló que la perspectiva de género es una categoría de análisis para comprender las diferencias entre hombres y mujeres, y el enfoque de género es una categoría de análisis y metodológica que incluye al mismo tiempo la perspectiva de género ${ }^{10}$. Esta diferenciación en mi criterio sigue siendo confusa y poco clara.

Desde este punto de vista, quisiera llamar la atención desde la filosofía para poder comprender los conceptos de manera separada, identificándolos con dos laborales completamente distintas y que, por lo tanto, pertenecen al desarrollo del quehacer diferente.

Nietzsche es considerado un perspectivista, y específicamente, puede entenderse cuando Nietzsche introduce la metáfora de la mirada de la rana y el águila, en la que la mirada de la rana, al querer abarcar la totalidad, se queda paralizada con lo que observa, mientras que, por el contrario, la mirada del águila puede mirar en perspectiva, se aleja y se acerca; su mirada es una mirada de acción, porque puede aproximarse lo más cerca posible y además alejarse ${ }^{11}$.

10 De la siguiente manera se refirió el documento: "Perspectiva de género es una categoría de análisis que hace referencia al tipo de relaciones que se establecen entre hombres y mujeres de una sociedad particular, con base en las características, roles, oportunidades y posibilidades que el grupo social asigna a cada uno de aquellas y aquellos. Enfoque de género es una herramienta analítica y metodológica que integra la categoría perspectiva de género y permite dar cuenta de la forma en que interactúan las diferencias de género y cómo ello genera desigualdades entre hombres y mujeres" (Comisión de Género, 2019, p. 7).

11 Nietzsche utiliza la metáfora de la rana y el águila para indicar dos tipos de perspectivas en las que los hombres se aproximan a la verdad. Las dos están condicionadas por el cuerpo. La rana siente la pesadez de su cuerpo al mirar hacia el cielo, con actitud poco profunda, queriendo abarcar la totalidad. La mirada de rana es principalmente la mirada del metafísico. Por el contrario, la perspectiva del águila depende del ángulo al que se quiere aproximar. La mirada del águila es más profunda por la forma como se acerca o se aleja de lo que quiere ver. Entre otros textos, se puede consultar el aforismo 2 del texto Más allá del bien y del mal: el crepúsculo de los ídolos. 
Por lo tanto, entiendo que las teorías que construyen modelos de justicia y específicamente se ubican desde el feminismo, hacen referencia a la perspectiva, la cual construye y justifica una mirada diferente para comprender los problemas de las mujeres. En otras palabras, la perspectiva de género son aquellas teorías y modelos de justicia que justifican una mirada diferenciada para resolver los problemas de las mujeres.

Por su parte, el concepto de enfoque hace referencia al método, y método, en griego antiguo, es camino; esto es, el paso a paso por el cual se transitan los propósitos y objetivos a alcanzar. Así las cosas, una vez justificado un modelo de justicia que implica la revisión de los problemas de las mujeres de manera diferencial, la perspectiva de género requiere de un método para la aplicación específica en los casos en concreto, a saber: el enfoque.

\section{Elementos para la construcción del enfoque de género}

En el marco de la coherencia ${ }^{12}$ del derecho, la construcción de un enfoque de género se encuentra determinada por diferentes leyes y pronunciamientos constitucionales a nivel regional, que justifican la inclusión de una mirada diferente en relación con los problemas de las mujeres, y esto no se presenta como algo contradictorio con el principio de imparcialidad del derecho, en la medida en que el problema en concreto no se puede solucionar desde ahí, como se ha venido decantando hasta el momento. Lo que ha generado, por el contrario, la utilización del mismo (el principio de imparcialidad) es que se escondan formas de opresión tras el concepto metafísico de imparcialidad. Esto hace necesario poner el ojo en el principio de igualdad, que requiere la mirada diferenciada de las instituciones públicas, en los casos en los que se pueda demostrar empíricamente el sufrimiento de las experiencias de injusticia que han sido ocultadas por las comunidades a través de la asignación de roles y estereotipos.

Así las cosas, la jurisprudencia de la Corte Interamericana de Derechos Humanos y los tribunales constitucionales busca instaurar la necesidad de fallar con enfoque de género, lo cual contribuye a la construcción de mecanismos legales internacionales e internos que logren solucionar los problemas que se presentan, y con ello, reconoce la necesidad de instaurar dispositivos que comprendan de manera diferenciada las desigualdades sociales y, en especial, la desigualdad basada en el género.

En el marco regional del Sistema Interamericano para la Protección de los

12 Se busca que los sistemas jurídicos sean coherentes y consistentes. En el primer caso, la coherencia permite que el sistema global del derecho sea visto como una totalidad que tenga sentido a partir de la construcción de valores comunes de la sociedad. En palabras del profesor MacCormick, "es la propiedad de un conjunto de proposiciones, que tomadas conjuntamente, tienen sentido en su totalidad”. Y por otro lado, las consistencias hacen referencia a que dentro de las normas en específico no existan contradicciones, esto es, un P y un no P. (2016). 
Derechos Humanos, la sentencia Algodoneros vs. México señala la necesidad de que los Estados consoliden herramientas que permitan el acceso de las mujeres a la justicia de una manera efectiva. Para ello, tendrá que buscar dispositivos que permitan la eliminación de los estereotipos que se edifican a propósito del género y del sexo.

Así, por ejemplo, la sentencia 2015-620 10 de 672, de la Suprema Corte de la Justicia, en México, en la revisión de un caso de violencia sexual en el trabajo, señaló lo siguiente,

[...] de los criterios sostenidos por el Comité para la Eliminación de la Discriminación contra la Mujer, se advierte que dicho hostigamiento conforma una conducta de tono sexual que, aun cuando puede no incluir algún contacto físico, atenta contra la libertad, dignidad e integridad física y psicológica de las mujeres al ser una expresión de abuso de poder que implica la supremacía masculina sobre éstas, al denigrarlas y concebirlas como objetos.

Por otro lado, en Chile, desde la rama judicial emanó el Cuaderno de buenas prácticas para incorporar perspectiva de género en las decisiones judiciales (2019), en el que se muestra la necesidad de incluir el enfoque de género en las decisiones judiciales:

Otra cuestión que queda clara es que la intervención del Tribunal debe orientarse con decisión desde una perspectiva de género, porque en la fenomenología de violencia contra la mujer, como se evidencia en los informes aludidos, ella tiene, por esta misma situación, una condición intrínseca de vulnerabilidad, de manera que, protegerla bajo esa premisa, es lo que mejor le permite una expectativa de igualdad que debe complementarse con medidas específicas (p. 61).

Por su parte, el Tribunal Constitucional del Perú, reconoce las desigualdades estructurales a las que se enfrenta la mujer en los diferentes espacios públicos y privados, y a pesar del avance normativo para garantizar las igualdades entre las personas, la cultura y la estructura generan problemas que no permiten que se materialicen eficazmente estos objetivos constitucionales. Por consiguiente, mediante la sentencia Num. 014792018-PA/TC, introduce la obligación a todas las instancias decisionales y en especial a la jurisdicción de introducir dentro de las decisiones el enfoque de género, entendido como:

[...] una nueva mirada a la desigualdad y a la situación de vulnerabilidad de las mujeres, se presenta como una herramienta metodológica que necesariamente debe ser empleada en el ámbito institucional (y también en el ámbito privado), ya que ayuda a la materialización de las medidas públicas adoptadas para lograr una real igualdad en derechos entre hombres y mujeres. (Cuaderno de buenas prácticas para incorporar perspectiva de género en las decisiones judiciales (2019)) 
En Argentina, por su parte, es para destacar la Ley Micaela, en la que es obligatorio que todas y todos los funcionarios públicos deberán recibir capacitación sobre género y sobre violencia de género. Es importante señalar que el movimiento feminista en Argentina ha generado gran impacto dentro de las instituciones, lo que permite que desde este lugar se presenten varias propuestas que involucren el enfoque de género. Entre otras cosas, en el año 2018, se realizó la XIV Conferencia Bienal de la International Association of Women Judges (IAWJ), en que participaron 78 países que hacen consciente la necesidad de incluir el enfoque de género.

Específicamente en Colombia, la Corte Constitucional ${ }^{13}$ ha determinado la necesidad de incluir el enfoque de género en las decisiones judiciales, toda vez que, en diferentes ocasiones, la Corte Constitucional Colombiana ha puesto en evidencia cómo las instituciones públicas y las autoridades judiciales fallan con base en estereotipos, lo que conduce a generar formas de discriminación dentro de las instituciones públicas. Así las cosas, la Corte Constitucional pone de relieve la necesidad de educar a las autoridades en la aplicación del enfoque de género.

A partir de lo anterior, y del análisis jurisprudencial internacional, considero que la aplicación del enfoque de género requiere de la cimentación específica en las diferentes jurisdicciones; por ejemplo, debe ser diferente en lo laboral o en lo penal o en las jurisdicciones especiales. Sin embargo, el enfoque de género deberá reunir unos mínimos a los que se han puesto de acuerdo los diferentes jueces constitucionales en América Latina, estos son los siguientes, a saber:

\section{- Acceso a la justicia de manera igual}

El enfoque de género como una metodología, busca mostrar a los juzgadores la problemática de las mujeres en los contextos sociales; por consiguiente, el juzgador o juzgadora que deba tomar decisiones respecto a la violencia deberá ser consciente de los estereotipos y roles asignados en los que pone a la mujer en desventaja para poder tomar decisiones que no impliquen vulneraciones a los derechos de las mujeres, asignándole más cargas o culpabilizándola de los hechos.

Así las cosas, si bien en principio las personas deben ser tratadas de manera igual, el juzgador o juzgadora deberá prever situaciones de asimetría de poder y si nos encontramos en relación con un caso en que la mujer se encuentra en desventaja por las condiciones de género, deberá apoyar a la mujer en el desarrollo del caso, independientemente de la jurisdicción, con el fin de asegurar que en efecto las partes sean iguales y no exista una que por cuestiones culturales y sociales tenga

13 Entre otras sentencias, revisar la sentencia T- 590 de 2017, T-2287-2018, T-735 de 2017, T-299 de 2018, T-677 de 2011. 
mejores garantías dentro de los procesos.

\section{- Identificar categorías sospechosas}

El juzgador para fallar con enfoque de género deberá identificar categorías sospechosas, las cuales, según la Corte Constitucional Colombiana, son criterios no taxativos que se utilizan dentro de las relaciones de las personas, tales como raza, sexo, nacionalidad, entre otras, para garantizar privilegios a un sector de la población en detrimento de otro sector. Así las cosas, el juez deberá estar atento, en el sentido de identificar en la narración del caso y en el discurso de los intervinientes algún lenguaje de discriminación con referencia a la víctima o identificando en la víctima algunos miedos o temores a lo que se pueda enfrentar en el proceso, y que se encuentran anclados a marcos de discriminación.

\section{- Aplicación de las fuentes internacionales}

Los jueces deberán anclar el problema de la violencia de género a un proyecto internacional que busca eliminar las causas que generan opresión y discriminación. Por esta razón, el juez deberá conocer todos los instrumentos internacionales que defienden y promueven la defensa de los derechos de las mujeres, con el fin de aplicarlos dentro de las decisiones judiciales.

\section{- Pruebas, testimonios y expertos}

Las pruebas y la carga de la prueba deberán pensarse en favor de la mujer. Esto no quiere decir que el juez tenga que fallar únicamente con el relato de la víctima, sino que tiene que flexibilizar el principio de más allá de la duda razonable para ajustarse a elementos específicos de contextos de violencia a los que se ven sometidas las mujeres, y en este contexto, ajustar el relato de la víctima para identificar elementos probatorios específicos de los entornos en los que se encuentra la mujer y reconstruir el caso con otros matices, más allá de la confrontación de los testimonios.

El testimonio de la víctima debe ser recolectado por expertos que manejen de manera diferencial el enfoque de género. En la mayoría de los casos, los jueces buscan identificar respuestas específicas, por lo cual se pueden hacer preguntas que le generen a la víctima nuevas formas de violencia y por lo tanto, revictimizarla. De esta manera, el testimonio deberá construirse en un escenario en donde la víctima no tenga miedo de hablar y no se sienta cuestionada en su relato, lo que hace necesario que el testimonio sea recogido por un grupo de expertos.

\section{- La debida diligencia}

Es necesario en principio que las autoridades en las diferentes jurisdicciones sean competentes para actuar de manera diligente y efectiva ante la denuncia de la víctima, en la cual se pueda proteger de una manera razonable la integridad física y mental de las personas que se encuentren 
expuestas ante situaciones de violencia. Esto implica en consecuencia la necesidad de introducir mecanismos específicos e instituciones para que se pueda cumplir con este requisito en concreto.

\section{- Reparar de manera proporcional al daño}

Es importante que la reparación del daño se realice con estándares nacionales e internacionales del daño moral, material y principalmente de los daños constitucional y convencional, como lo son la sanción penal, disciplinaria, laboral, entre otras del agresor. También es importante la reparación de carácter económico; sin embargo, es mucho más necesaria la inclusión de nuevas formas de reparación simbólicas y al mismo tiempo, que permitan espacios y escenarios de transformación en el trabajo.

\section{CONCLUSIONES}

1. La violencia contra la mujer se encuentra estructurada desde esferas que son invisibles y que, por lo tanto, requieren de un esfuerzo educativo y cultural para poner de relieve las prácticas incrustadas en las creencias de las personas y que permiten la violencia estructural y directa. La violencia directa es una forma que puede medirse de manera concreta y específica, lo cual permite que las autoridades judiciales reaccionen de una manera más inmediata en este panorama. Sin embargo, la violencia invisible que se permea en la cultura y en los dispositivos de la sociedad requiere de nuevos análisis para su desligamiento.

2. Los términos perspectiva de género y enfoque de género requieren de conceptualizaciones diferentes. El primero hace referencia a los modelos de justicia contemporáneos, específicamente el feminismo, que justifica y legitima la mirada diferenciada del problema de las mujeres en la sociedad. El segundo es el método que las autoridades públicas aplicarán en cada uno de los casos a resolver, cuando efectivamente nos encontremos ante situaciones que generen discriminación por causa del género.

3. El enfoque de género como método puede construirse desde la Jurisprudencia de la Corte Interamericana de Derechos Humanos y desde los diferentes tribunales constitucionales en América Latina, los cuales han emanado una serie de pronunciamientos en donde señalan cuáles son los elementos que se deben tener en cuenta al momento de tomar decisiones con base en enfoque de género. Estos, entre otros, pueden ser: garantizar el acceso a la justicia de manera igual; identificar categorías sospechosas; aplicar las fuentes internacionales; cambiar las normas respecto a la recolección de las pruebas, los testimonios y la necesidad de la intervención de expertos en género; la debida diligencia; reparar de manera proporcional al daño. 


\section{REFERENCIAS BIBLIOGRÁFICAS}

\section{Libros consultados}

Aguilera Peña, M. (2014) Contrapoder y justicia guerrillera. Fragmentación política u orden insurgente en Colombia (1952-2003). Bogotá: Universidad Nacional de Colombia, Biblioteca IEPRI.

Alves, D. (2017). Rés negras, juízes brancos: uma análise da interseccionalidade de gênero, raça e classe na produção da punição em uma prisão paulistana. Revista CS, 21, 97-120. Cali, Colombia: Facultad de Derecho y Ciencias Sociales, Universidad ICESI.

Bobbio, N. (2008). El problema de la guerra y las vías de paz. Barcelona: Editorial Gedisa.

Centro Nacional de Memoria Histórica. (2013). iBasta YA! Colombia memorias de Guerra y Dignidad. Informe General grupo Memoria Histórica. Bogotá: Centro Nacional de Memoria Histórica.

Centro Nacional de Memoria Histórica. (2017). La guerra inscrita en el cuerpo. Informe General grupo Memoria Histórica. Bogotá: Centro Nacional de Memoria Histórica.

Céspedes, L., Chaparro, N., Vargas, S. (2014). Metodologías en el estudio de la violencia sexual en el marco del conflicto armado interno. Colombia internacional, 80.

Fraser, N. y Honneth, A. (2018) ¿Redistribución o Reconocimiento? Madrid: Paideia.

Galtung, J. (1969[1930]). Una teoría estructural de la integración. Revista de la Integración. Buenos Aires.

Galtung, J. (1998). Tras la violencia, 3R: Reconstrucción, reconciliación, resolución. Afrontando los efectos visibles de la guerra y la violencia. España: Bakeaz.

Galtung, J. (1984). iHay alternativas! 4 caminos hacia la paz y la seguridad. Madrid: Editorial Tecnos.

Gómez-Jutinico, L.A., Falla Ospina, M.F., Cadavid Peláez, N., Ardila Ávila L.L., y Colmenares Sanabria, C. (2018). "Retos en el posconflicto respecto de la violencia sexual causada a las mujeres en el marco del conflicto armado". En Discusiones sobre la implementación del acuerdo final de paz: Una mirada en perspectiva de la ciencia social. Bogotá: Editorial Universidad Libre.

Honneth, A. (2011). La sociedad del desprecio. Madrid: Editorial Trotta. 
Insuasty Rodríguez, A. Valencia Grajales, J. y Restrepo Marín, J. (2016). Elementos para una genealogía del paramilitarismo en Colombia. Medellín: Grupo de Investigación y Editorial Kavilando.

Langa, A. (2010). Los conflictos armados en el pensamiento económico. Instituto de Estudios sobre Conflictos y Acción Humanitaria (IECAH). Recuperado de https://www.iecah.org/images/stories/ publicaciones/documentos/descargas/documento7.pdf

Lederach, J. (2016) La imaginación Moral. El arte y el alma de la construcción de paz. Bogotá: Editorial Plural.

López, I. (2007). El enfoque de género en la intervención social. Recuperado de https://xenero.webs.uvigo.es/profesorado/ carmen_verde/manual.pdf.

MacCormick. N. (2011). Instituciones del Derecho. Madrid: Marcial Pons Ediciones.

MacCormick. N. (2016). Retórica y Estado de Derecho. Lima: Palestra Editores.

Meron, T. (1993). Rape as a Crime under International Humanitarian Law. The American Journal of International Law, 87(3), 424-428.

Niño, N. (2018). Discusiones sobre la implementación del acuerdo final de paz: Una mirada en perspectiva de la ciencia social. Bogotá: Universidad Libre.

Nietzsche, F. (1990). Humano, demasiado humano. Madrid: Akal.

Nietzsche, F. (2000). La Genealogía de la Moral. Madrid: Alianza.

Nietzsche, F. (2006). Sobre Verdad y Mentira en el Sentido Extramoral. Bogotá: Jorge Castillo.

Nietzsche, F. (2009). Más allá del bien y del mal. Madrid: Alianza Editorial.

Quesada Jiménez. J. (2014). Estereotipos de género y usos de la lengua. Un estudio descriptivo en las aulas y propuestas de intervención didáctica. Tesis doctoral. Universidad de Murcia, España.

Rojas Gómez, G. (22 de febrero de 2018). Jueces deben aplicar perspectiva de género en casos de violencia entre parejas: Corte Suprema. Recuperado de http://www.cortesuprema.gov.co/corte/index. php/2018/02/22/jueces-deben-aplicar-perspectiva-de-genero-encasos-de-violencia-entre-parejas-corte-suprema/.

Romero, M. (2003). Paramilitares y autodefensas, 1982-2003. Bogotá: Editorial Planeta - Instituto de Estudios Políticos y Relaciones Internacionales, Universidad Nacional de Colombia. 
Ryan, S. I. (1999). From the Furies of Nanking to the Eumenides of the International Criminal Court: The Evolution of Sexual Assaults as International Crimes. Pace International Law Review, 11(2), 447-486.

Schmitt, C. (2012). Posiciones ante el derecho. Madrid: Editorial Tecnos.

Sisma Mujer. (2012). Boletín No. 12. Del fin de la Guerra a la erradicación de la violencia sexual contra las mujeres: un reto para la paz. Corporación Sisma Mujer. Bogotá.

\section{Normas nacionales}

Congreso de la República. Constitución Política de Colombia.

Acuerdo Final para la Terminación del Conflicto y la Construcción de una Paz Estable y Duradera. Recuperado de http://www. altocomisionadoparalapaz.gov.co/procesos-y-conversaciones/ Documentos\%20compartidos/24-11-2016NuevoAcuerdoFinal.pdf

Congreso de la República. Colombia. Ley 975 del 2005. Por la cual se dictan disposiciones para la reincorporación de miembros de grupos armados organizados al margen de la ley. Julio 25. Diario Oficial 45.980.

Presidente de la República de Colombia. Decreto Ley 121 de 2017. Por medio del cual se establecen instrumentos jurídicos para facilitar y asegurar la implementación y el desarrollo normativo del Acuerdo Final para la Terminación del Conflicto y la Construcción de una Paz Estable y Duradera. Recuperado de http://es.presidencia.gov.co/normativa/normativa/ DECRETO\%20121\%20DEL\%2026\%20ENERO\%20DE\%202017. pdf.

\section{Normas internacionales}

Consejo de Seguridad ONU. Resolución 1325 (2000), Pub. L. No. 1325 (2000), 17017432 (2000).

Convención sobre la Eliminación todas las Formas de Discriminación contra la Mujer (CEDAW). (1981). Recuperado de https://www. unicef.org/panama/spanish/MujeresCo_web.pdf.

Convención Interamericana para Prevenir, Sancionar y Erradicar la Violencia contra la Mujer. "Convención De Belem Do Para". (1994). Recuperado de: https://www.oas.org/juridico/spanish/ tratados/a-61.html.

Naciones Unidas, Cuarta conferencia sobre la mujer. (1995). Recuperado de $\quad$ https://www.un.org/womenwatch/daw/beijing/pdf/ Beijing\%20full\%20report\%20S.pdf.

Naciones Unidas, A. G. Convención para la Eliminación de la Discriminación contra la Mujer (1981). 
Colombia. Jurisdicción Especial para la Paz. Comisión e género. Exp. 2017-120080101268E. Colombia. 2018.

\section{Jurisprudencia de la Corte Interamericana de Derechos Humanos}

Corte Interamericana de Derechos Humanos. La Masacre de Mapiripán vs. Colombia. Recuperado de http://www.corteidh.or.cr/docs/casos/ articulos/seriec_134_esp.pdf

Corte Interamericana de Derechos Humanos. La Masacre de la Rochela vs. Colombia. Recuperado de http://www.corteidh.or.cr/docs/casos/ articulos/seriec_163_esp.pdf

Corte Interamericana de Derechos Humanos. Masacres de Ituango vs. Colombia. Recuperado de http://www.corteidh.or.cr/docs/casos/ articulos/seriec 148 esp.pdf

Corte Interamericana de Derechos Humanos. Masacre de Las Dos Erres vs. Guatemala. Recuperado de www.corteidh.or.cr/docs/casos/ articulos/seriec 213 esp.doc

Corte Interamericana de Derechos Humanos. Caso Gonzales y otras (Campo algodonero) vs. México. Recuperado de http://www. corteidh.or.cr/docs/casos/articulos/seriec_205_esp.pdf

Corte Interamericana de Derechos Humanos, caso Masacre del Mozote y lugares aledaños vs. El Salvador. Recuperado de http://corteidh. or.cr/docs/casos/articulos/seriec_252_esp.pdf.

Corte Interamericana de Derechos Humanos, Comunidad Indígena Yakye Axa vs. Paraguay. Recuperado de http://www.corteidh.or.cr/docs/ casos/articulos/seriec 125 esp.pdf.

Corte Interamericana de Derechos Humanos, caso de la Comunidad Indigena Xakmok vs. Paraguay. Recuperado de http://www. corteidh.or.cr/docs/casos/articulos/seriec 214 esp.pdf.

Corte Interamericana de Derechos Humanos, caso Artavia Murillo y otros (fecundación in vitro) vs. Costa Rica. Recuperado de: http://www. corteidh.or.cr/docs/casos/articulos/seriec_257_esp.pdf

Corte Interamericana de Derechos Humanos, Caso del Penal Miguel Castro Castro vs. Perú. Recuperado de http://www.corteidh.or.cr/ docs/casos/articulos/seriec 160 esp.pdf

\section{Informes de la Comisión Interamericana de Derechos Humanos}

Comisión Interamericana de Derechos Humanos. Raquel Martín de Mejía vs. Perú Informe No. 5/ 1996.. 
Comisión Interamericana de Derechos Humanos. (2017). Comunicado de prensa. Recuperado de https://www.oas.org/es/cidh/prensa/ comunicados/2017/208.asp

\section{Jurisprudencia de la Corte Europea de Derechos Humanos}

European Court of Human Rights. (1997). Case of Aydin v. Turkey (57/1996/676/866).

\section{Jurisprudencia de Tribunales Penales Internacionales}

International Criminal Tribunal for Rwanda. Prosecutor v. Jean-Paul Akayesu, Trial Judgment, Case No ICTR-96-T (1998).

International Criminal Tribunal for the fomer Yugoslavia. Prosecutor v. Anto Furundžija, Trial Judgment, Case No IT-95-17/1-T, Icty 118 (1998).

\section{Jurisprudencia de la Corte Constitucional Colombiana}

Corte Constitucional de Colombia [C.C.], mayo16, 2008, M.P. J.C. Triviño, Sentencia T-496/08, [Colom.].

Corte Constitucional de Colombia [C.C.], abril 3, 2008, M.P. J.C. Triviño, Sentencia T-299/08, [Colom.].

Corte Constitucional de Colombia [C.C.], abril 14, 2008, M.P. M.J. Cepeda Espinosa, Sentencia Auto 092/08, [Colom.].

Corte Constitucional de Colombia [C.C.], agosto 22, 2008, M.P. Gloria Stella Ortiz Delgado, Sentencia T-338/08, [Colom.].

Corte Constitucional de Colombia [C.C.], septiembre12, 2011, M.P. J.C. Henao Pérez, Sentencia T-677/11, [Colom.].

Corte Constitucional de Colombia [C.C.], enero 27, 2015, M.P. L.E. Vargas Silva, Sentencia Auto 009/15, [Colom.].

Corte Constitucional de Colombia [C.C.], enero 22, 2016, M.P. L.E. Vargas Silva, Sentencia T-012/16, [Colom.].

Corte Constitucional de Colombia [C.C.], mayo16, 2016, M.P. J.I. Pretelt Chaljub, Sentencia T-241/16, [Colom.].

Corte Constitucional de Colombia [C.C.], septiembre 21, 2017, M.P. A.R Ríos, Sentencia T-590/17, [Colom.].

Corte Constitucional de Colombia [C.C.], diciembre 15, 2017, M.P. A.J. Lizarazo Ocampo, Sentencia T-735/17, [Colom.].

Corte Constitucional de Colombia [C.C.], abril 12, 2018, M.P. C.P. Schlesinger, Sentencia T-126/18, [Colom.]. 


\section{Jurisprudencia de la Corte Suprema de Justicia}

Corte Suprema de Justicia [C.S.J.], Sala de Casación Penal, noviembre 20, 2014, M.P. J.L. Barceló Camacho, Sentencia SP15901-2014, [Colom.].

Corte Suprema de Justicia [C.S.J.], Sala de Casación Civil, febrero 21, 2018, M.P. M. Cabello Blanco, Sentencia STC2287 -2018, [Colom.].

\section{Jurisprudencia del Consejo de Estado}

Consejo de Estado [C.E.], Sección Tercera, octubre 9, 2014, C.P. R.J. Pazos Guerrero, Sentencia -2002-00228-01/29033, [Colom.]. 